\title{
Survey of Dermatophytes in Stray Cats with and without Skin Lesions in Northern Italy
}

\author{
Daniela Proverbio, Roberta Perego, Eva Spada, Giada Bagnagatti de Giorgi, \\ Alessandra Della Pepa, and Elisabetta Ferro
}

Dipartimento di Scienze Veterinarie per la Salute, la Produzione Animale e la Sicurezza Alimentare, Università degli Studi di Milano, Via G. Celoria 10, 20133 Milano, Italy

Correspondence should be addressed to Daniela Proverbio; daniela.proverbio@unimi.it

Received 10 December 2013; Revised 7 April 2014; Accepted 24 April 2014; Published 13 May 2014

Academic Editor: Remo Lobetti

Copyright (C) 2014 Daniela Proverbio et al. This is an open access article distributed under the Creative Commons Attribution License, which permits unrestricted use, distribution, and reproduction in any medium, provided the original work is properly cited.

\begin{abstract}
The aim of this study was to determine the prevalence of dermatophytes in stray cats with and without clinical lesions from different colonies in rural and urban areas of Milan and surroundings in northern Italy. Stray cats (273) were caught during a trap-neuterrelease (TNR) program conducted in different colonies of northern Italy in both rural and urban areas. Each cat was examined in dark environment with a Wood's lamp prior to sample collection. Hair or scales exhibiting typical fluorescence were removed with a pair of sterile hemostats and cultured. The hair of all cats was then sampled by Mackenzie modified brush technique regardless of the presence or absence of skin lesions attributable to dermatophytosis. All the hair samples were subjected to fungal culture. 15 cats were positive (5.5\%). Microsporum canis was the most common dermatophyte isolated (13/15). The only other isolated dermatophyte was Trichophyton mentagrophytes (2/15). Our estimated prevalence of dermatophytes in stray cats was much lower than other Italian studies on the same population.
\end{abstract}

\section{Introduction}

Various fungal organisms, as dermatophytes or saprophytes fungi, are frequently found on the feline hair coat $[1,2]$. The most diffuse zoophilic dermatophytes that are primarily animal pathogens belong to the Microsporum and Trichophyton genera and some species of them may cause dermatophytosis in humans $[1,3]$.

The prevalence of dermatophytes in cats has been reported with much variability, depending on geographical location, season of sampling, and clinical and living conditions [4].

There are few data regarding the prevalence of Microsporum canis in stray cats. In asymptomatic or random screening stray cats the world prevalence of dermatophytes varies from $5 \%$ to $50 \%$ [5-10]. In Italy, dermatophytes were isolated from $27 \%$ to $50 \%$ of stray cats regardless of the presence of clinical sings $[7,9]$.

In most worldwide and Italian studies, M. canis is the most isolated dermatophyte in stray cats and its prevalence varies from $0 \%$ to $47.4 \%$ [5-10] while Trichophyton mentagrophytes is rarely isolated and its prevalence varies from $0 \%$ to $11.9 \%[5-10]$.

The knowledge of health status of free-roaming stray cats is important in the assessment of animal welfare and to obtain information about pathogens and diseases located in each environmental region.

The aim of this study was to improve the information regarding the prevalence of dermatophytes in stray cats. We have evaluated a large sample of stray cats in northern Italy, since this area has not previously been examined.

\section{Material and Methods}

2.1. Feline Population. Hair samples were collected from 273 stray cats with and without clinical signs living in northern Italy. The cats were caught by volunteers between April 2008 and February 2010 during a trap-neuter-release (TNR) program approved by the local authority of the city council, conducted as described previously [11]. The colonies 
TABLE 1: Epidemiological data of the population, prevalence of dermatophytes in relation to the epidemiological data and $P$ value of Fisher's exact test and Odds ratio (OD) for each risk factor considered in a 273 stray cats with and without clinical signs living in north Italy.

\begin{tabular}{|c|c|c|c|c|c|}
\hline Variable & Categories & $\begin{array}{l}\text { Number of } \\
\text { subject }\end{array}$ & $\%$ & $\begin{array}{c}\text { Number }(N) \text { and } \\
\text { percentage }(\%) \text { of cats } \\
\text { positive for dermatophytes }\end{array}$ & $\begin{array}{l}P \text { value of Chi square test } \\
\text { and Odds ratio (OD) }\end{array}$ \\
\hline \multirow{2}{*}{ Sex } & Female & 199 & 72.9 & $14 / 199(7.0 \%)$ & \multirow{2}{*}{$\begin{array}{c}P=0.067, \mathrm{OD}=5.52 \\
(\mathrm{CI}=0.71-42.78)\end{array}$} \\
\hline & Male & 74 & 27.1 & $1 / 74(1.4 \%)$ & \\
\hline \multirow{2}{*}{ Age } & Young & 120 & 44.0 & $9 / 120(67.5 \%)$ & \multirow{2}{*}{$\begin{array}{l}P=0.198, \mathrm{OD}=1.99 \\
\quad(\mathrm{CI}=0.69-5.75)\end{array}$} \\
\hline & Adult & 153 & 56.0 & $6 / 153(3.9 \%)$ & \\
\hline Breed & $\begin{array}{c}\text { European } \\
\text { domestic cats }\end{array}$ & 273 & 100 & $15 / 273(5.5 \%)$ & - \\
\hline \multirow{2}{*}{ Habitat } & Urban & 149 & 54.6 & $11 / 149(7.4 \%)$ & \multirow{2}{*}{$\begin{array}{c}P=0.133, \mathrm{OD}=2.39 \\
\quad(\mathrm{CI}=0.74-7.71)\end{array}$} \\
\hline & Rural & 124 & 45.5 & $4 / 124(3.2 \%)$ & \\
\hline \multirow{2}{*}{ Coat } & Short & 259 & 94.9 & $14 / 259(5.4 \%)$ & \multirow{2}{*}{$\begin{array}{c}P=0.781, \mathrm{OD}=0.74 \\
\quad(\mathrm{CI}=0.09-6.09)\end{array}$} \\
\hline & Long & 14 & 5.1 & 1/14 (7.1\%) & \\
\hline \multirow{2}{*}{ Season } & Warm & 129 & 47.3 & $4 / 129(3.1 \%)$ & \multirow{2}{*}{$\begin{array}{c}P=0.100, \mathrm{OD}=0.39 \\
\quad(\mathrm{CI}=0.12-1.25)\end{array}$} \\
\hline & Cold & 144 & 52.7 & $11 / 144(7.6 \%)$ & \\
\hline \multirow{2}{*}{ Skin lesion } & Yes & 63 & 23.1 & $3 / 63(4.8 \%)$ & \multirow{2}{*}{$\begin{array}{c}P=0.770, \mathrm{OD}=0.83 \\
\quad(\mathrm{CI}=0.23-3.02)\end{array}$} \\
\hline & No & 210 & 76.9 & $12 / 210(5.7 \%)$ & \\
\hline \multirow{2}{*}{$\begin{array}{l}\text { Positivity to } \\
\text { dermatophytes }\end{array}$} & Yes & 15 & 5.5 & - & - \\
\hline & No & 258 & 94.5 & - & - \\
\hline \multirow{2}{*}{$\begin{array}{l}\text { Positivity to } \\
\text { saprophytic fungi }\end{array}$} & Yes & 201 & 73.6 & $2 / 201(1.0 \%)$ & \multirow{2}{*}{$\begin{array}{c}P=0.0001^{*}, \mathrm{OD}=0.05 \\
\quad(\mathrm{CI}=0.01-0.21)\end{array}$} \\
\hline & No & 72 & 26.4 & $13 / 72(18.1 \%)$ & \\
\hline
\end{tabular}

${ }^{*} P$ value $<0.05$.

were located both in rural and urban areas of Milan and surroundings in areas adjacent to human structures such as schools, hospitals, farms, and homes.

Cats were anaesthetized and, before surgery, were evaluated, by clinical examination, for general health and presence or absence of ectoparasites. Unhealthy cats were defined as cats with the presence of one or more of the following clinical abnormalities: lymph node enlargement, pale mucous membranes, stomatitis, or signs of ocular and respiratory infections.

2.2. Sample Collection. After anaesthesia each cat was examined in a dark environment with the Wood's lamp for several minutes prior to sample collection. Hair or scales exhibiting typical fluorescence were removed with a pair of sterile hemostats and cultured. Then the hair coat of all 273 cats was brushed with a sterile toothbrush using the modified Mackenzie collection method [1, 12].

To evaluate seasonal trends in dermatophyte infection, the samples from each group were categorized according to the sampling period as either warm season samples (collected from April through September) or cold season samples (collected from October through March).

2.3. Fungal Culture. All the hair samples were inoculated by gently imprinting the toothbrush onto the surface of $9 \mathrm{~cm}$ Petri dishes containing Sabouraud dextrose agar (added with chloramphenicol $0.5 \%$ and actidione $0.4 \%$ ). The Petri dishes were incubated upside down in an oven (MICRA, I.S.Co.,
Zetalab S.R.L., Italy) in the dark at a constant temperature of $25^{\circ} \mathrm{C}$ and examined daily for three weeks. After three weeks the colonies in the medium were macroscopically and microscopically examined and identified to species level as dermatophytes.

2.4. Statistical Analysis. The Fisher's exact test was used to evaluate differences in the prevalence of the different species of isolated dermatophytes. Epidemiological data from cats were analysed by Chi-square test, in order to identify significant differences between the observed dermatophytes prevalence according to age, gender, breed, hair coat length, skin lesions, habitat, and season. The software used was MedCalc (Version 11.6.1.0, Mariakerke, Belgium) and $P$ value $<0.05$ was considered significant.

\section{Results}

Age, gender, breed, hair coat length, and habitat (urban or rural areas) were recorded for all cats (Table 1). Age was estimated by dentition and animals were classified as young $(<1$ year of age) and adult ( $>1$ years of age) [13]

The prevalence of dermatophytes on the hair coat of overall stray cats of our study in northern Italy was 5.5\% (15/273). Only two dermatophytes were cultured and both were zoophilic: Microsporum canis $(86.7 \%-13 / 15)$ and Trichophyton mentagrophytes $(13.3 \%-2 / 15)$ (Table 1$)$. Sex, age, hair coat length, season of sampling, and geographical habitat did not show a significant association with dermatophytes 
prevalence. There were no positive cultures among cats identified as positive (20/273) under Wood's lamp. The ectoparasites found in cats were flea $(9.16 \%-25 / 237)$ and tick $(1.46 \%-4 / 237)$.

\section{Discussion}

The prevalence of dermatophytes in our study, on stray cats in northern Italy, was $5.5 \%$ which is lower compared with the prevalence found in other studies conducted on stray or feral population (35.2\% in New Zealand [5], 25.6\% in feline colonies of Iran [6], and 29.4\% in Portugal [10]), but similar to the prevalence of $5 \%$ found in the UK [8].

When considering only the Italian stray cats studies, the prevalence of dermatophytes is much higher compared with our result. A study conducted in different parts of Siena (central Italy) found a prevalence of $50 \%$ in asymptomatic stray cats [7] and a stray cat study conducted in the north east of Italy detected a prevalence of $27 \%$ [9].

Possible explanations for the low prevalence in our study could be due to the good general health status [14] of the population that we examined, as determined in a previous study [11].

In our study, Microsporum canis was the more frequent isolated dermatophyte (86.7\%) and this is in agreement with other feline studies conducted in Italy and worldwide [2, 5$7,10,15,16]$.

We found no significant association between dermatophyte presence and sex, age, hair coat length, season of sampling, geographical habitat (i.e., rural or urban), or the presence or absence of parasites. Our results differ from the higher prevalence of young and long-haired cats found in previous studies $[6,17,18]$. The low overall prevalence of dermatophytes found in our study and the presence of only $5.1 \%$ long-haired cats in our sample might represent bias. Statistical analysis could be limited in some groups because of the sample size, and so some associations may be affected by type I errors; that is, in our case, no association was recorded between presence of the cats with dermatophytosis and age or no association was recorded between dermatophyte presence and cats hair coat length.

There were no positive cultures among the cats identified as positive (20/273) through examination using a Wood's lamp. It must be considered that the Wood's lamp facilitates identification of only $50 \%$ of the strains of $M$. canis, and this limitation may be particularly significant with the low positive prevalence found in our study $[14,16]$. It must be emphasized that the field situation in which the research was done may have affected the accuracy of execution of the examination conducted by the Wood's lamp. In fact the environment was not completely dark and the analysis time was often reduced because the cats were anaesthetized.

No conclusions were possible with respect to an association between prevalence and breed because all the cats examined in this study were domestic shorthair (DSH). The overall number of cats with ectoparasites was low, and no relationship was found between the presence of ectoparasites and dermatophytosis prevalence, even though microtrauma resulting from pruritus induced by ectoparasites might predispose cats to $M$. canis infection $[19,20]$.

\section{Conclusions}

In conclusion, estimated prevalence of dermatophytes $(M$. canis and T. mentagrophytes) in stray cats of northern Italy was much lower than other Italian studies on the same population.

\section{Conflict of Interests}

The authors declare that there is no conflict of interests regarding the publication of this paper.

\section{References}

[1] K. A. Moriello and D. J. DeBoer, "Fungal flora of the haircoat of cats with and without dermatophytosis," Journal of Medical and Veterinary Mycology, vol. 29, no. 5, pp. 285-292, 1991.

[2] K. A. Moriello, G. Kunkle, and D. J. De Boer, "Isolation of dermatophytes from the haircoats of stray cats from selected animal shelters in two different geographic regions in the United States," Veterinary Dermatology, vol. 5, no. 2, pp. 57-62, 1994.

[3] C. A. Outerbridge, "Mycologic Disorders of the Skin," Clinical Techniques in Small Animal Practice, vol. 21, no. 3, pp. 128-134, 2006.

[4] Y. Al-Doory, T. E. Vice, and F. Olin, "A survey of ringworm in dogs and cats," Journal of the American Veterinary Medical Association, vol. 153, no. 4, pp. 429-432, 1968.

[5] M. G. Carman, F. M. Rush-Munro, and M. E. Carter, "Dermatophytes isolated from domestic and feral animals," New Zealand Veterinary Journal, vol. 27, no. 7, pp. 136-144, 1979.

[6] A. R. Khosravi, "Fungal flora of the hair coat of stray cats in Iran," Mycoses, vol. 39, no. 5-6, pp. 241-243, 1996.

[7] C. Romano, L. Valenti, and R. Barbara, "Dermatophytes isolated from asymptomatic stray cats," Mycoses, vol. 40, no. 11-12, pp. 471-472, 1997.

[8] A. Patel, D. H. Lloyd, and A. I. Lamport, "Survey of dermatophytes on clinically normal cats in the southeast of England," Journal of Small Animal Practice, vol. 46, no. 9, pp. 436-439, 2005.

[9] A. Natale, A. Frangipane di Regalbono, G. Zanellato et al., "Parasitological survey on stray cat colonies from the Veneto region," Veterinary Research Communications, vol. 31, no. 1, pp. 241-244, 2007.

[10] A. Duarte, I. Castro, I. M. Pereira da Fonseca et al., "Survey of infectious and parasitic diseases in stray cats at the Lisbon Metropolitan Area, Portugal," Journal of Feline Medicine and Surgery, vol. 12, no. 6, pp. 441-446, 2010.

[11] E. Spada, D. Proverbio, A. della Pepa et al., "Seroprevalence of feline immunodeficiency virus, feline leukaemia virus and Toxoplasma gondii in stray cat colonies in northern Italy and correlation with clinical and laboratory data," Journal of Feline Medicine and Surgery, vol. 14, no. 6, pp. 369-377, 2012.

[12] C. Cafarchia, D. Romito, M. Sasanelli, R. Lia, G. Capelli, and D. Otranto, "The epidemiology of canine and feline dermatophytoses in southern Italy," Mycoses, vol. 47, no. 11-12, pp. 508-513, 2004 . 
[13] A. H. Sparkes, T. J. Gruffydd-Jones, S. E. Shaw, A. I. Wright, and C. R. Stokes, "Epidemiological and diagnostic features of canine and feline dermatophytosis in the United Kingdom from 1956 to 1991," Veterinary Record, vol. 133, no. 3, pp. 57-61, 1993.

[14] K. A. Moriello, "Important factors in the pathogenesis of feline dermatophytosis," Veterinary Medicine, vol. 98, no. 10, pp. 845895, 2003.

[15] A. R. Khosravi and M. Mahmoudi, "Dermatophytes isolated from domestic animals in Iran," Mycoses, vol. 46, no. 5-6, pp. 222-225, 2003.

[16] F. Mancianti, S. Nardoni, M. Corazza, P. D’Achille, and C. Ponticelli, "Environmental detection of Microsporum canis arthrospores in the households of infected cats and dogs," Journal of Feline Medicine and Surgery, vol. 5, no. 6, pp. 323-328, 2003.

[17] K. A. Moriello, "Practical diagnostic testing for dermatophytosis in cats," Veterinary Medicine, vol. 98, no. 10, pp. 859-895, 2003.

[18] E. Seker and N. Dogan, "Isolation of dermatophytes from dogs and cats with suspected dermatophytosis in Western Turkey," Preventive Veterinary Medicine, vol. 98, no. 1, pp. 46-51, 2011.

[19] ESCCAP, European Scientific Counsel Companion Animal Parasites, Superficial Mycoses in Dogs and Cats. ESCCAP Guideline 02, 2nd edition, 2011.

[20] K. A. Moriello and S. Newbury, "Recommendations for the management and treatment of dermatophytosis in animal shelters," Veterinary Clinics of North America-Small Animal Practice, vol. 36, no. 1, pp. 89-114, 2006. 

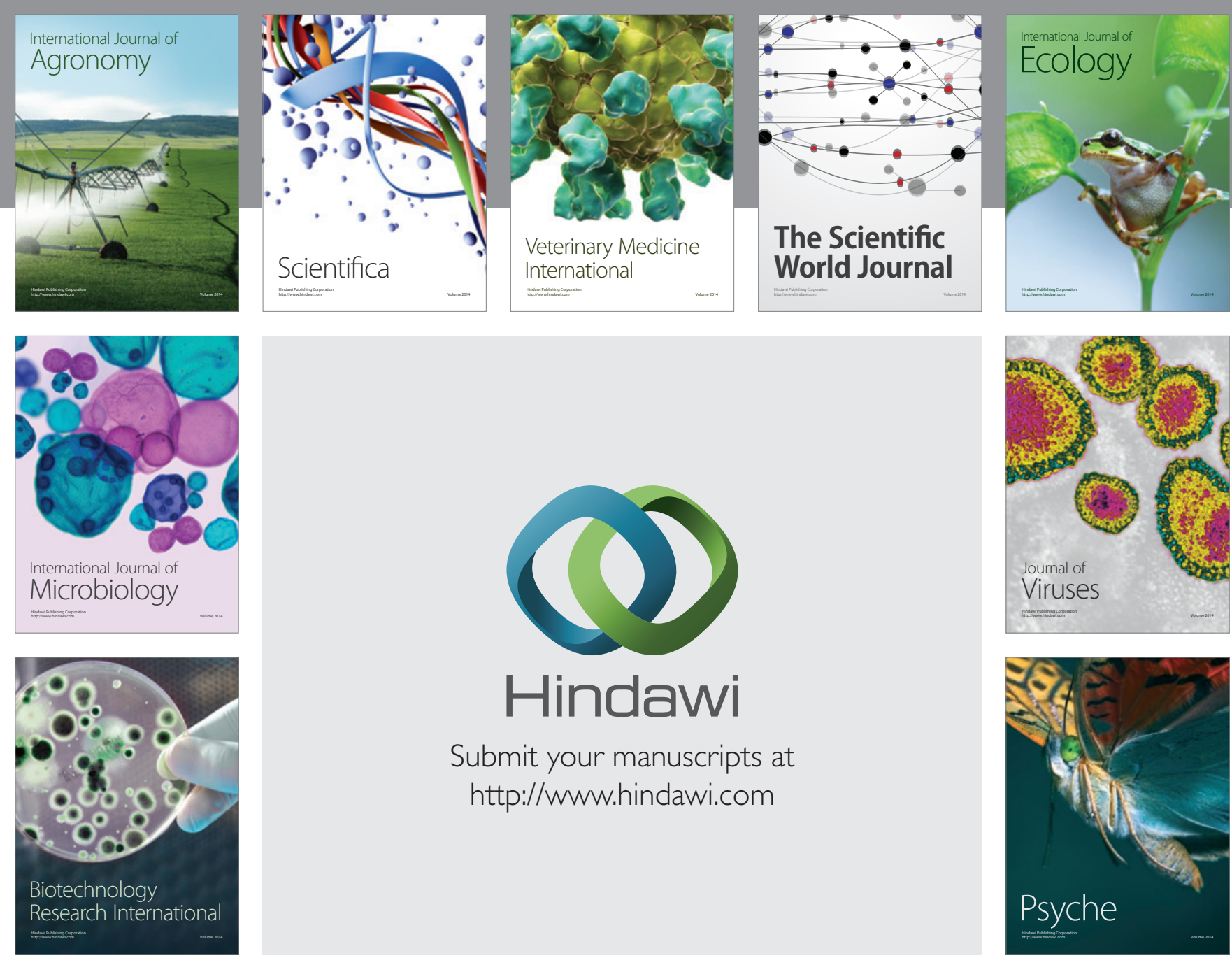

Submit your manuscripts at http://www.hindawi.com
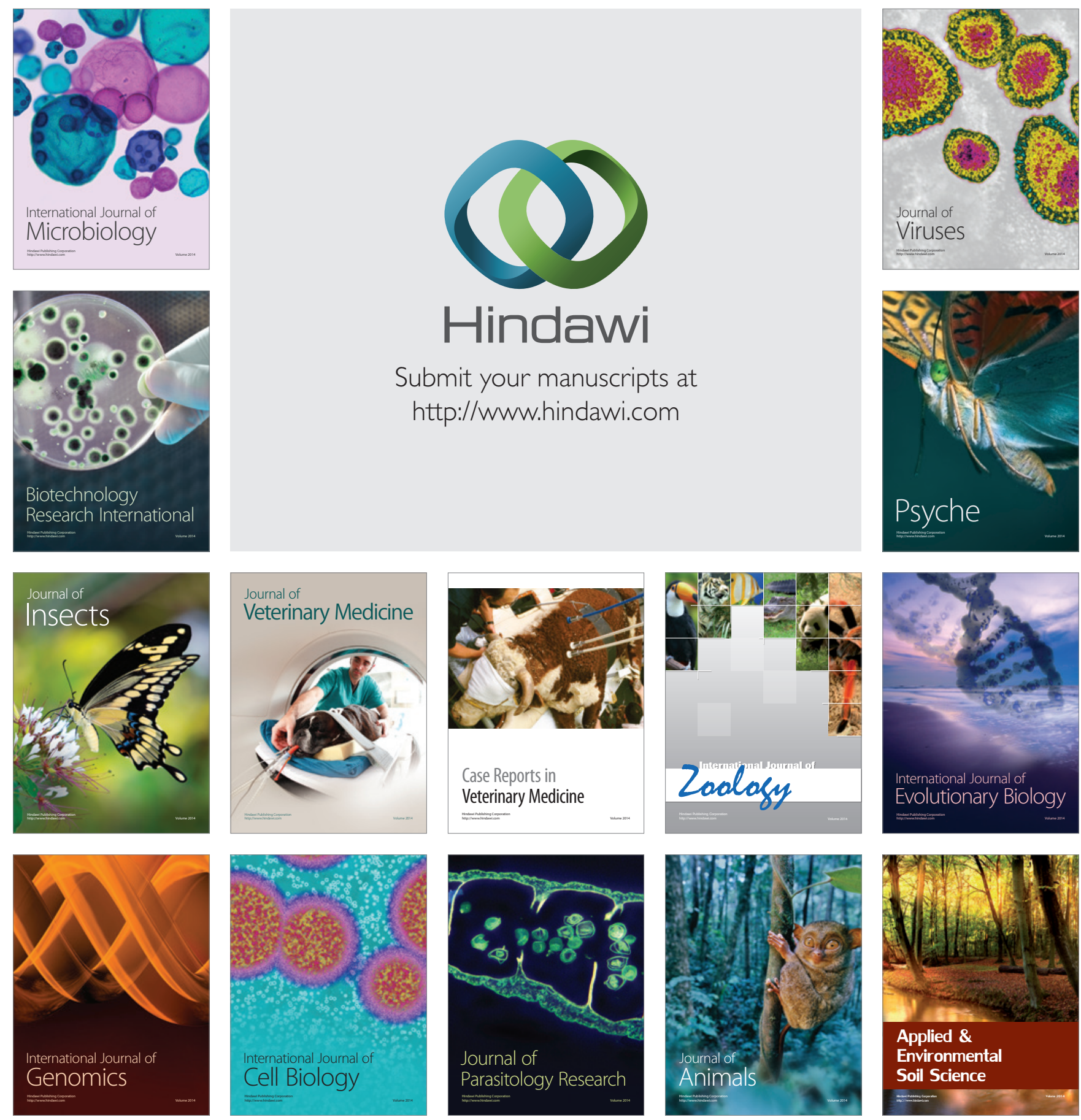